\title{
From planetary to space mining: prospects for sustainable development
}

\author{
Arkadiy $\mathrm{Ursul}^{1}$, and Tatiana $\mathrm{Ursul}^{2 *}$ \\ ${ }^{1}$ M.V. Lomonosov Moscow State University, 119991, Moskva, GSP-1, Leninskie gory, 1, str. 13, \\ Moskow, Russia \\ ${ }^{2}$ National University of Science and Technology MISIS (Moscow Institute of Steel and Alloys), \\ 119991, Leninskij Av., 4, Moskow, Russia
}

\begin{abstract}
The article considers sustainable mining development as one of the most important problems of achieving global stability as a solution to the contradiction between the growing needs of mankind and the presence of limits of the biosphere in their provision. It is expected that sustainable mountain development will continue in both the planetary and space dimensions, and these processes will unfold in close cooperation. Having joined the space industry, sustainable space mining will contribute to the formation of extraterrestrial basis of the future wide space exploration by mankind.
\end{abstract}

\section{Introduction}

After the United Nations Conference on Environment and Development (UNCED) in 1992 in Rio de Janeiro, the world community set a goal and adopted a strategy for transition from spontaneous to globally managed sustainable development (SD) as the main way of civilization survival. A definition of the SD concept was given in the book "Our Common Future", known as G.H. Brundtland and devoted to the scientific substantiation of the need for transition to SD. It was drawn to the future: "Sustainable development is development that meets the needs of the present without compromising the ability of future generations to meet their own needs". Thus, in particular, was defined the main goal of the necessity of transition to sustainable development - the future survival of the mankind [1].

\section{Sustainable mining development}

Preservation of the biosphere and survival of mankind is the cardinal purpose of the transition to sustainable development. The best case scenario for the future of our planet and mankind living on it involves the preservation of the biosphere as the natural basis of life of all the living and sophont.

Moreover, this includes the life of the population and a significant part of the biodiversity in such vulnerable ecosystems as mountainous regions (for example, 43 constituent regions of the Russian Federation have mountain ranges and uplands, and the total area occupied by

* Corresponding author: ursult@mail.ru 
them is $53.6 \%$ of the territory of Russia). The mountains occupy about one fourth of the planet's surface and are home to $12 \%$ of the world's population, they affect all processes in the rest of the planet. Mountainous areas are important for the existence of civilization, and for the evolution of the entire global ecosystem, which was highlighted in the Agenda 21 adopted by UNCED [2].

Mountainous areas more than other habitats are affected by the adverse effects of climate change, as well as the consequences of disasters in mountainous areas, such as flash floods, including floods from mountain lakes, as well as landslides, mudflows and earthquakes. At the same time, the mountains are sources of mineral resources and sources of fresh water supply, as well as hydropower resources (70\% of fresh water reserves and $50 \%$ of deposits of precious and non-ferrous metals are concentrated in the mountains).

This feature of mountainous areas requires special severe restrictions on economic activity and the implementation of "sustainable mining development". Therefore, in the documents of the UN dedicated to SD strategy, special attention was paid to the mountainous areas [3]. Mountainous regions are characterized by the fact that they are one of the most ecologically vulnerable areas and at the same time they are the ones that are affected by development of the most large-scale environmental management processes that cause negative impacts on the surrounding nature and people. "Sustainable mountain development" and "sustainable development of mountainous areas", although close, but not the same concepts. The latter concept focuses on mountainous areas, while the term "sustainable mining development" characterizes SD as mountainous areas and other territorial areas where sustainable mining can take place, for example, on plains or even outside the planet. This difference appears due to the fact that mining is associated not only with mountains and hills, but with a special human activity in the development of the Earth's interior in any other place on the planet, i.e. underground mining of minerals. Therefore, mining as an activity for the development of the Earth's interior allows both its planetary-terrestrial and cosmic expansion.

Mining, as a rule, is considered as a field of activity on the use of the earth's crust for the extraction of minerals, their primary processing, as well as related scientific research. However, this term has recently become used not only in the meaning of mining, but in the production of bitcoins and other crypto-currencies on mining farms and platforms. In the article, the concept of mining will be used in the context of mining, rather than cryptocurrency. Thus, a number of key concepts that originated and were used in the mining engineering receive their new, space and information, expansion. The humanity is now interested in mining SD not only in the "planetary-underground", but also the space perspective, since in the future these two processes will occur not only in parallel, but also cooperatively. SD can be implemented in two main variants - in the global-terrestrial one, in accordance with a modern concept, and the space one, as proposed by the founder of astronautics, K. Tsiolkovsky.

\section{Stable horizons of extraterrestrial mining}

The beginning of the interaction between mining engineering, mining and astronautics did not come by accident at the present time of space exploration. It became obvious that space activities would not continue to develop effectively without the "support" of the mining industry and its emergence beyond the terrestrial atmosphere. Along with this, both further space exploration and geospace safety promotion, i.e. protection of the planet against threats from space, will be impossible without development of space mining. It is appropriate to recall that $\mathrm{K}$. Tsiolkovsky proved the necessity of space exploration proceeding not only from the demands of social and economic development, but primarily from the need to ensure the safety and preservation of mankind [4]. He also reckoned the emergence of an "industry in the ether". Therefore the development of mining, and through it, the other industries, is in 
line with the reduction of anthropogenic pressure on the biosphere under the conditions of the population growth.

The development of space resources and their processing outside the Earth, directly in space, drastically changes the principles and trajectories of space missions, as well as the ways of creating space technology, bringing this technological process beyond the biosphere. The priority space resource is water. It can be found in circumterrestrial asteroids in the amount of several trillion tons. If it becomes possible to extract water from natural cosmic bodies (which decomposes under the influence of an electric current to oxygen and hydrogen) and other necessary products for space technology, and to produce fuel outside the planet on the basis of hydrogen, it will reduce the price of further space development by twenty times.

It is believed that the first space field is likely to be not asteroids (which may contain rare earth elements, platinoids and other rare and precious metals) but the Moon, where the priority extracted resource will be the water used to provide life support to people and fuel for rockets and space vehicles. The need to use lunar natural resources for the creation of lunar bases, the construction of space infrastructure for the purposes of further space exploration, including mine shafts, tunnels and other underground structures [5-11], especially for refueling space vehicles, attests to the early development of the Moon.

However, more than a thousand asteroids are flying near the Earth, and they can be achieved much more easily than the Moon. At the same time some of them represent a very serious threat to our planet, which is often reported by the media. However, the Moon still does not significantly affect the problem of geocosmic safety, while some asteroids and comets constitute threat to planet on a short-term horizon. It is evident that the asteroid-comet hazard $(\mathrm{ACH})$ has to be prevented and it can fundamentally affect the choice of further ways and methods of space activities, since security is always more important than commercial and other activities: in fact, it is also necessary to stand secure in order to develop economy. The basic idea of SD in its terrestrial and space variants is to ensure the safe existence of mankind. It is important not to place in jeopardy the ability of future generations to meet their needs and, above all, the basic need for a safe existence and sustainable development on Earth and in space. After all, the more space and objects of space will be mastered on a larger scale, the greater the chance of further continuation of mankind existence. K. Tsiolkovsky assumed that idea creating his space version of sustainable development beyond the planet. The recently deceased British physicist S. Hawking and American entrepreneur I. Mask, who founded SpaceX company in 2002 in order to colonize Mars, came to the same ideas. This colonization, in his opinion, will turn mankind into an interplanetary species and increase the probability of the survival of our civilization if some global space catastrophe occurs on Earth. Space mining can be the "key" to survivorship, which will destroy (or deflect from the planet) a dangerous asteroid, as it was already in art form demonstrated in the American fantasy film "Armageddon" at the end of the last century.

It is important to pay attention to a kind of "reverse effect" of new mining technologies developed for space needs: many traditional mining technologies cannot be used in the space mining industry, since space conditions fundamentally affect these technologies. The application of new physical principles and fundamentally new approaches to the creation of equipment will be required for space mining technologies. For example, in the future, there may be technologies for direct metal extraction, bypassing mining, processing and metallurgical processing, as is customary in "terrestrial" mining technologies. These new technologies seem to be more cost-effective in terms of the cost-benefit ratio, but what counts most is that they are environmental friendly and less material-intensive. This makes them more acceptable in case of implementation in terrestrial conditions, so the space mining options will significantly contribute to the transition to mining SD on a global scale.

Mining space technologies in the conditions of our planet in the coming decades can have a revolutionizing effect on the entire terrestrial mining industry. Therefore, when there arises 
an image of the mine of the future, it is important to consider the possibility of deploying space mining and its influence on underground works and structures.

Paying attention to the problem of material intensity, one should not overlook the energy problem, which is more fundamental and acts as one of the main ones in the process of transition to the SD. It is known that over a million tons of helium-3 isotope accumulated in the surface layer of the lunar soil (the regolith), which can be used as fuel for future thermonuclear reactors and which is sufficient to provide humanity with energy for many thousands of years. Since such fuel produces few carbon and toxic wastes, its environmental benefits attract the attention of power engineers and because of the helium-3 isotope, in the not too distant future the Moon can become one of the main space mines.

However, it is unlikely that the entire stock of this energy commodities will be sent to the planet and will continue to build up terrestrial energy production. The geocentric vision of "sustainable energy" development does not allow a significant and long-term extension of the mankind evolution. There is a limit to the production of energy on our planet because of its overheating, and this limit should not exceed a thousandth of the energy received from the Sun, consequently the further growth of energy use $d$ by mankind is expedient only with the wide development of energy processes outside the Earth. Creation of an industrial-energy base in space (primarily on the Moon) will make it possible to transfer both energy-intensive and environmentally harmful production from the Earth. This is a fairly obvious imperative and the goal of transition to space SD: the exploration of outer space should promote a global transition to $\mathrm{SD}$, and the space activity itself also has to become a sustainable process.

In the near space future, mankind will have to massively ship the production of energy and materials outside the planet, instead of deploying this industry in undeveloped territories, for example, in deserts, the Arctic, the Antarctic or in the oceans and seas. The main reason for the relocation of the energy and some other industries outside the Earth is related to the transition to SD and especially with a number of environmental issues, such as global warming and depletion of the world's fossil fuel and energy resources with the increase of energy consumption. Therefore, the development of any new terrestrial territories, for example, the ocean, is economically inefficient and environmentally impractical. In the case of the development of space bodies, a new anthropogenically-space method and a method of preserving the terrestrial biosphere, as well as the creation on it of the most favorable conditions for the existence of mankind and other forms of life, appear. Therefore, those projects that in the acceptable future can be implemented in space, are hardly worthwhile to implement on the planet.

A fundamental conclusion about the need for the future to "split" production into terrestrial, mainly agricultural and space, mainly industrial, between which the products of activity can and will be exchanged has already been made on the basis of an analysis of current trends in the environmentalization of economic and other anthropogenic activities in the context of achieving global sustainability. Agricultural production in the perspective of the transition to SD should fit into the biosphere, using intensively-ecologized methods of economy management. The strategic perspective of global-space production split is the most natural and effective one and is understandable in terms of ensuring eco-and geo-security of the civilization existence.

The relocation of the industry, including mining, beyond the planet is based on its intensive xenobiotic action on the biosphere, however, it will no longer harm the biosphere outside the planet. The relocation of certain enterprises and even industries to space or their further development on the planet will be determined, first of all, by considerations of the optimal achievement of the global-space stability of the "man-society-nature" system.

It is therefore important to use space objects and their resources in order not to violate international law. This way of development of the space mining industry is not only more in line with modern space international law, but also a further transition to SD in its global and 
extraterrestrial directions. If the development of scientific trends and industries engaged in exploration activities and mining operations goes along the "merchant path", then its prospects will be very dangerous for the transition of the world community to SD. Getting an opportunity to do business with space resources at a certain stage can even promote these private developments. But in the future, it is fraught with littering of the planet by space resources, which, after use, will become terrestrial waste, and which will significantly impede the achievement of global sustainability.

\section{Conclusion}

Thus, it can be considered that mining beyond the planet might become more actively involved in space activity, and can become its most important component and give a new impetus and direction for the development of extraterrestrial spaces. It is possible to talk about such interaction between astronautics and extraterrestrial mining, when in a certain sense they are able to become components of each other in the foreseeable future.

If in the first stage of human space expansion the "starting base" was the Earth and its resources, then in the foreseeable future, not only the planet, but also celestial bodies, not only their information, but also real-energy resources will be relevant. This is made possible by the predicted development of space mining, which will divide the history of space exploration into two historical stages - before the emergence and development of space mining and the continuation of space activities with the development of mining outside the Earth. Thus, space mining will contribute to the sustainable development of space exploration on an extraterrestrial basis, which will open unlimited possibilities for the penetration of mankind into the universe.

\section{References}

1. K.E. Tsiolkosky, Reaktivnye letatel'nye apparaty. Sobr. soch. (Akademii nauk SSSR, Moscow, 1954)

2. F.I. Yagodkin, A.Y. Prokopov, M.S. Pleshko, A.N. Pankratenko, IOP Conference Series: Earth and Environmental Science, 87(6), 062014 (2017)

3. F. Yagodkin, M. Pleshko, A. Prokopov, Procedia Engineering, 206, 293-298 (2017)

4. M. Pleshko, B. Meskhi, M. Pleshko, MATEC Web of Conferences, 170, 03023 (2018)

5. A. Pankratenko, M. Pleshko and A. Isaev, MATEC Web of Conferences, 7, 02026 (2018)

6. B. Meskhi, M. Pleshko, Y. Buligin, L. Alexeenko, M. Molev, IOP Conference Series: Earth and Environmental Science, 90(1), 012217 (2017)

7. M. Pleshko, A. Pankratenko, A. Revyakin, E. Shchekina, S. Kholodova, E3S Web of Conferences, 33, 02036 (2018)

8. M. Pleshko, I. Voinov, A. Revyakin, MATEC Web of Conferences, 106, 05004 (2017)

9. O.V. Nagovicyn, PhD Thesis, (1995)

10. A.D. Ursul, Actual problems of aviation and aerospace systems: processes, models, experiment, 21, 1(42) (2016)

11. A. A. Zhuchenko, A.D. Ursul, Strategiya adaptivnoj intensifikacii selskohozyajstvennogo proizvodstva, (Shtiintsa, Kishinyov, 1983) 